\title{
A SURVEY OF GEORGIAN STUDENTS' CAREER CHOICES
}

\author{
Mariam Mardaleishvili*, ${ }^{1 *}$ atin Sabauri ${ }^{2}$ \\ ${ }^{1}$ MA Student of Ivane Javakhishvili Tbilisi State University, Faculty of Education and Psychology, \\ GEORGIA, mariamardaleishvili@gmail.com \\ ${ }^{2}$ Ivane Javakhishvili Tbilisi State University, GEORGIA, tinatinsabauri@yahoo.de \\ ${ }^{*}$ Corresponding Author
}

\begin{abstract}
The article reviews career guidance as a support mechanism for professional education and considers it as a necessary tool to choose the right career. The need of providing advisory service to young people and adolescents regarding professional guidance, identifying strengths and weaknesses, realizing one's interests and inclinations may arise at various stages of life: after the completion of basic level, finishing secondary school, starting a professional career, changing a job, career planning, starting a family, unemployment. In each of these situations young people and adolescents may need help from professional consultants.

Within the scope of the article secondary and tertiary level students and parents from Georgia have been surveyed. The questionnaires were designed to identify students' and parents' attitudes towards professional orientation classes, how they evaluate the importance of career guidance at school, which grades they consider most suitable for professional orientation classes. The survey attempts to find out who gives advice to Georgian secondary-level students when making career choices from students' and parents' perspectives. Tertiary level students were also surveyed in an attempt to find out what or who influenced them when choosing careers and to evaluate their satisfaction with their decisions. It also looks at the level of parents' involvement in the implementation of professional guidance at schools.
\end{abstract}

Through the analysis and processing of qualitative questionnaires we summed up the main challenges and problems that hinder making meaningful career choices. The article draws up some conclusions and recommendations important for Georgian environment.

Keywords: career guidance, professional orientation, vocational education.

\section{INTRODUCTION}

Career choice is an individual and social phenomenon consisting of a range of scientific and paradigm perspectives. It may be understood as a process of identifying various options, alternatives, skills and abilities. It includes different activities such as: informing, counselling, evaluation of competences, decision making and career planning. 
The need of providing advisory service to young people and adolescents regarding professional guidance, identifying strengths and weaknesses, realizing one's interests and inclinations may arise at various stages of life: after the completion of basic level, finishing secondary school, starting a professional career, changing a job, career planning, starting a family, unemployment. In each of these situations young people and adolescents may need help from professional consultants.

Career guidance as a policy is of great importance. During the last decade it has been actively discussed by various international organizations, including OECD, World Bank, European Commission and its agencies. The latter focuses on the systematic analysis of the data from fifty countries.

Like each person, each country is individual and unique. Every country has its culture and infrastructure to provide career resources and services (Manual of Career Guidance, 2015).

In 2016 secondary level students and their parents were surveyed in three regions of Georgia: Tbilisi, Kvemo Kartli and Kakheti. The survey aimed at evaluating professional orientation classes at the secondary level, involvement of parents and satisfaction with the professional orientation classes offered at schools.

63 secondary-students participated in the survey. To the question: "Who discusses questions related to professional orientation with you?" answers fell into the following categories:

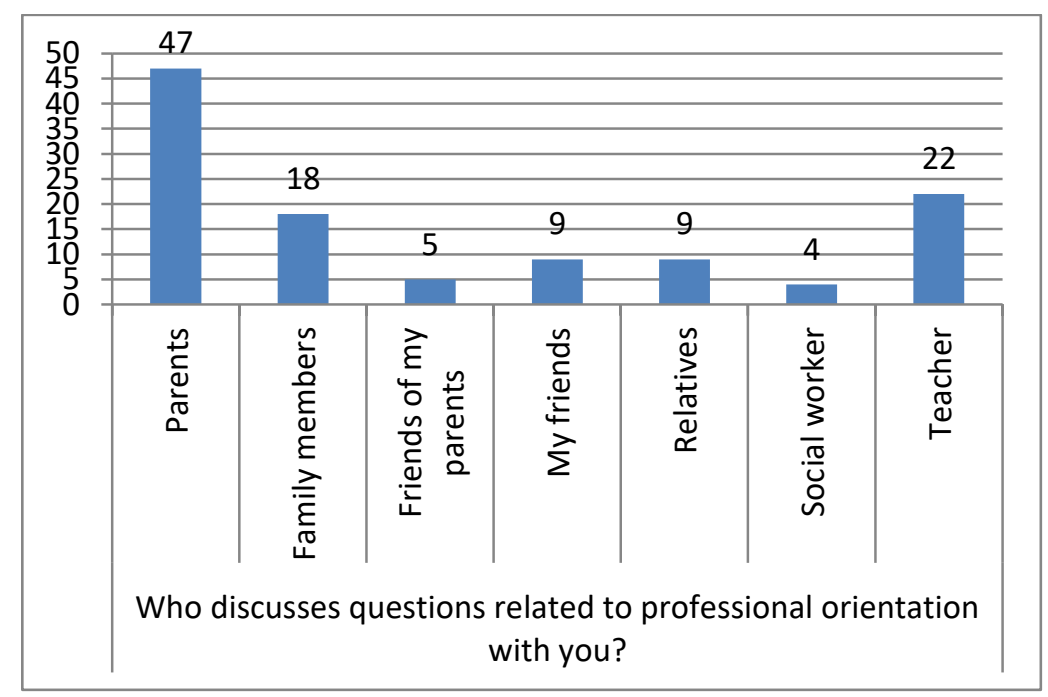

The majority of students - 55 out of 63 - want to regurarly have professional orientation classes at school, 2 students are against.

Most of the students think that professional orientation classes should be introduced in the nineth grade.



Parents' (18 parents participated) attitude towards the importance of professional orientation classes at school is as follows: 


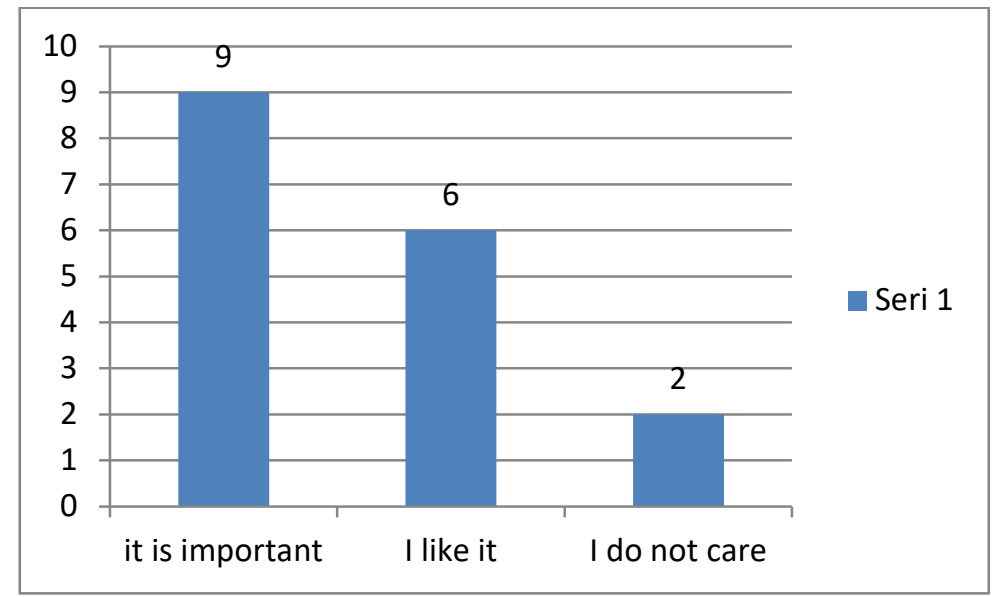

To the question: "who helps your child to make a career choice", answers were following:

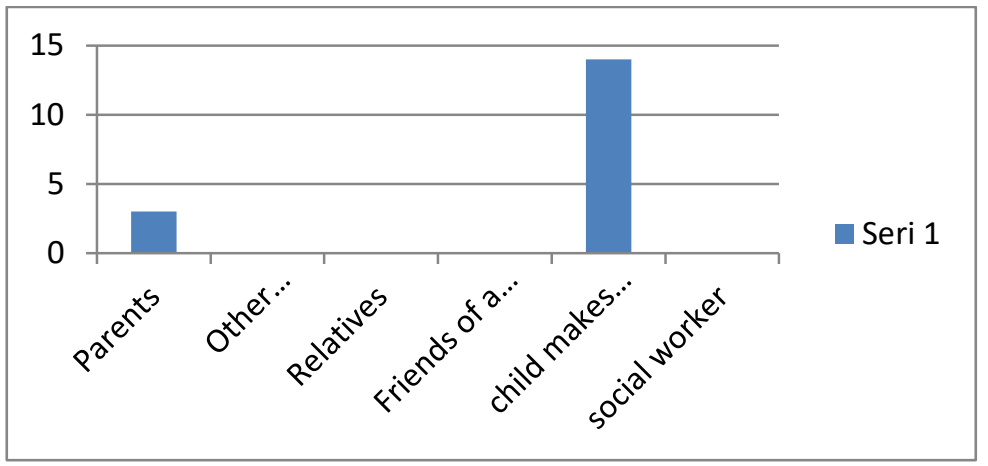

Most of the parents (13 out of 18) say that they rarely or never discuss issues related to professional orientation. Most of them also think (10 out of 18) that their children make career choices according to prospects for employment. The majority of parents (14 out of 18) consider that $9^{\text {th }}$ grade is the most suitable period to introduce professional orientation classes at school.

In order to define how adults choose a career, we administered confidential questionnaires to first year students of Business Schools at llia State University in 2016. The results show that most students chose their professions because they were interesting, prestigious and highly-paid.

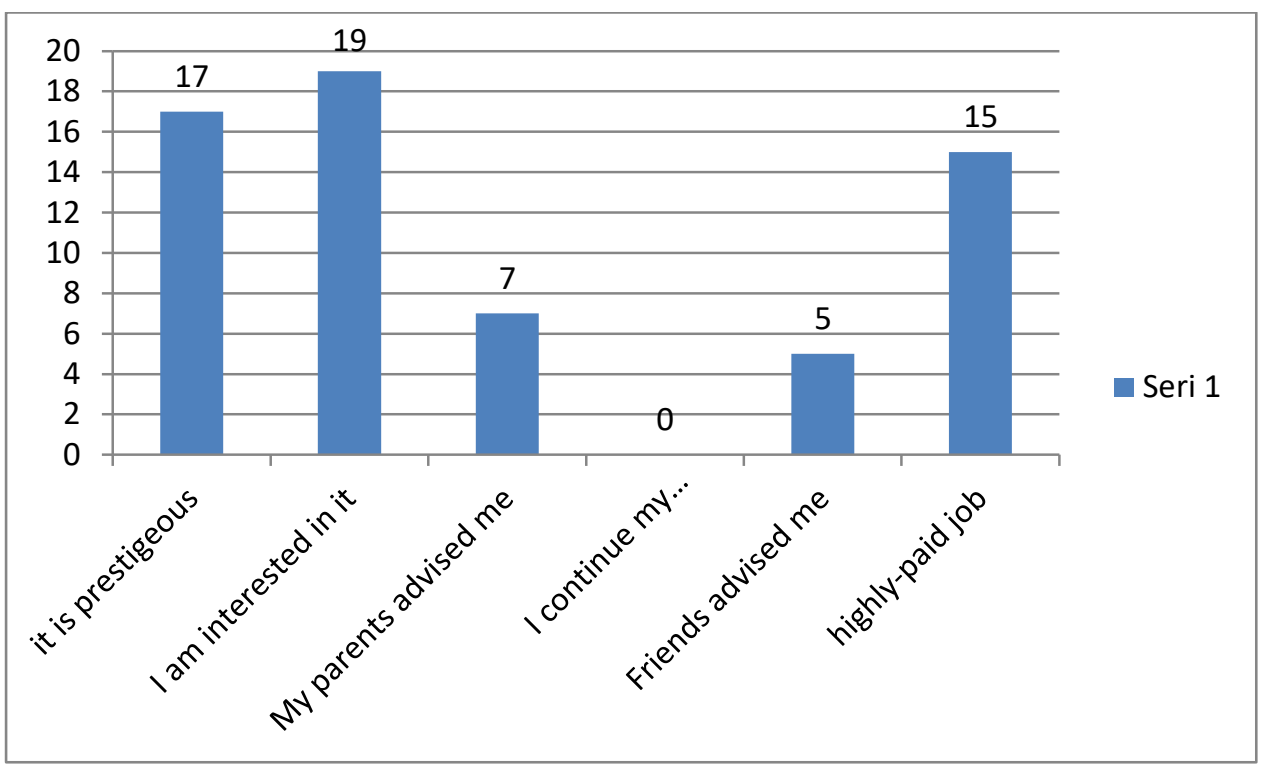

23 students are satisfied with their choices, 1 is not satisfied, while 6 think that it is not clear for them yet.

Answers to the question: "My succsess in my profession depends on" were following: 


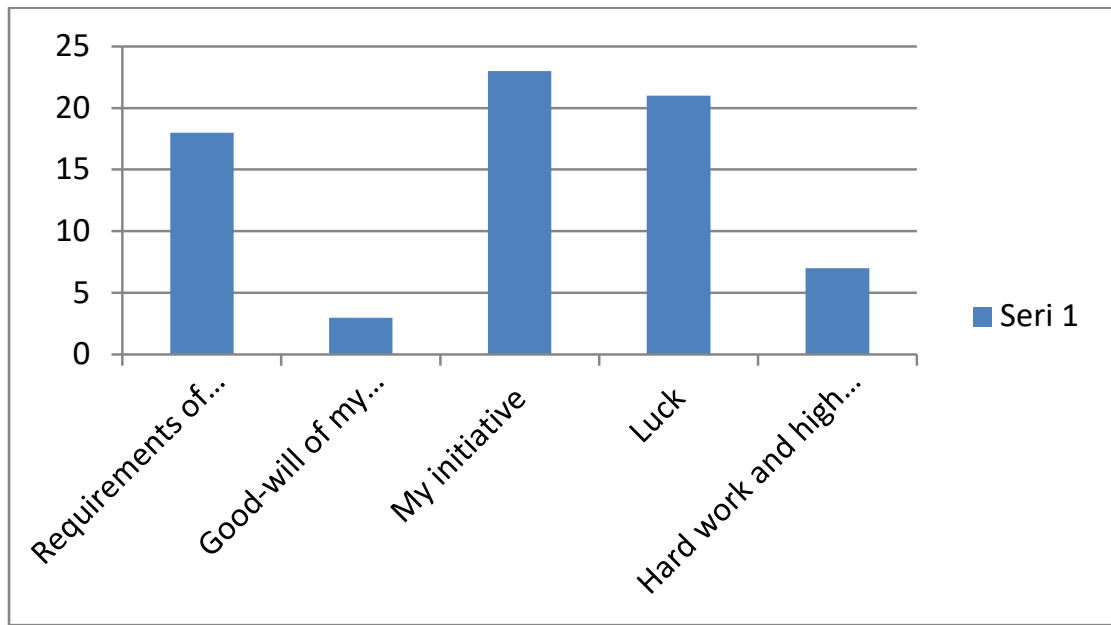

18 students think that they would choose the same professions once again, 3 students think that they would definitely change their professions, 12 are not sure.

As we can conclude from the results above it is important to:

1) Provide individual and group professional orientation classes.

2) Analyse student's professional interests, inclinations and skills in terms of the requirements of labour market.

3) Identify interest spheres of students through face-to-face interviews.

4) Plan externship visits after individual and group consultations with students considering their interests, inclinations and skills.

5) Contact the employees of a hosting company supervising students. Record and document their analysis and evaluation. This will allow us to establish correspondence between the students' expectations and interests to their skills and performance.

6) Plan meetings with the representatives of various fields. Discussion and conversation held in a friendly environment will help young people identify characteristics of relevant professions helping them take realized decisions.

7) Raise parents' awareness on professional orientation and involve them in relevant campaigns, events and activities.

8) Provide training for consultants of professional orientation ensuring the implementation of professional orientation classes and students' inclusion.

\section{REFERENCE LIST}

Füsun Akkök, 2015. Handbook for Career Guidance. Technical Assistance to VET and Employment Reforms in Georgia EUVEGE

Ch. Schiermann, B.Ertelt, J. Katsarov, R. Mulvey, H. Reid and P. Weber. 2014. NICE Handbook NICE Handbook for the Academic Training of Career Guidance and Counseling Professionals. HdBA

Matching Skills and Labour Market Needs Building Social Partnerships for Better Skills and Better Jobs. 2014. World Economic Forum Global Agenda Council on Employment

Career Guidance in Education, Profession and Labour Market Management. 2013. Slovak University of Technology in Bratislava

Career Guidance A Handbook For Policy Makers. 2004. Organization for Economic Co-operation and Development (OECD) European Commission (EC)

Torino Process 2014 GEORGIA

Sectorial Policy Support Program: Employment and Vocational Education and Training 